\title{
Proceeding
}

Supplementary Issue: Summer Conferences of Sports Science. First International Conference in Iraq on Sport for Peace, 4 April 2019. Baghdad Science Institute, Baghdad, Iraq.

\section{The mediating role of green creativity in the relationship between proactive green innovation, reactive green innovation and the performance of Green product development: A case of Thai sports manufacturing firms}

\author{
NATNAPORN AEKNARAJINDAWAT ${ }^{1}$, KITTISAK JERMSITTIPARSERT² \\ ${ }^{1}$ Graduate School, Suan Sunandha Rajabhat University, Bangkok, Thailand \\ ${ }^{2}$ Social Research Institute, Chulalongkorn University, Bangkok, Thailand
}

\begin{abstract}
The study is carried out to examine the mediating role of green creativity in the relationship between proactive green innovation, reactive green innovation and the performance of Green product development. The study has used the survey-based methodology to achieve the research objectives. The SEM-PIs is used to analyse the data collected from the manufacturing firms in the Thai Sports industry. For the cumulative green activity Some managerial mediations like reimbursement plans, brainstorming competitions and team building are might be good options. Thirdly between the green product development performance and PGI there is an important role of green creativity, as in organizations increment in green creativity also matters a lot. The benefit of green innovations is comprising with lost cost to deal with pollution, the effectiveness and productivity will be high, accountability of law will be less developing the reputation of business and the stakeholder sad customers will provide additional support. For the future research author can use the longitudinal study and can make discussion about differences of the finding in different time period. Secondly the research can conduct a study on different countries and compare the finding with current study. For the future study in conceptual framework human resource practices can also be considered. Keywords: Green; Creativity innovation; Sports; Thailand.
\end{abstract}

Cite this article as:

Aeknarajindawat, N., \& Jermsittiparsert, K. (2019). The mediating role of green creativity in the relationship between proactive green innovation, reactive green innovation and the performance of Green product development: A case of Thai sports manufacturing firms. Journal of Human Sport and Exercise, 14(5proc), S2290-S2303. doi:https://doi.org/10.14198/jhse.2019.14.Proc5.45

Corresponding author. Social Research Institute, Chulalongkorn University, Bangkok, Thailand.

E-mail: bakhteeyar@gmail.com

Supplementary Issue: Summer Conferences of Sports Science. First International Conference in Iraq on Sport for Peace, 4 April 2019. Baghdad Science Institute, Baghdad, Iraq.

JOURNAL OF HUMAN SPORT \& EXERCISE ISSN 1988-5202

(c) Faculty of Education. University of Alicante

doi:10.14198/jhse.2019.14.Proc5.45 


\section{INTRODUCTION}

With the growth of industrial evolution, the side effects of industrial activities on environment have develop as an international issue (Haseeb, Kot, Hussain, \& Jermsittiparsert, 2019; Jermsittiparsert \& Chankoson, 2019; Kasayanond, Umam, \& Jermsittiparsert, 2019; Somjai \& Jermsittiparsert, 2019). In the agenda of corporate management, the idea of protecting the environmental management has gained a lot of consideration for the elimination of environmental pressure.

These days companies are attentive towards the development of green production and products as green management can earn high profits, because generally the green products are acceptable. The of green product development performance (GPDP) ca be defined as developing the new concept about green practices or green processes, green products (GP)and services which new, original and beneficial (Mathiyazhagan, Sengupta, \& Mathivathanan, 2019). In simple words for the successful planning of developing GP it's important to incorporate mindset of management with the development activities of GP. According to the Weng et al. (2015) that investments in green product process and innovations are beneficial in future for the business. So, companies must know about the importance of green innovation (GI) and also recognize that green products will be common in international market and development of green products will be leading in future (Weng, Chen, \& Chen, 2015). Additionally, the green products have more attention because the people are well aware with environmental issue. The developing the new products and services that are environment friendly are important for business success, are meeting the customers demand regarding environment protection. Though according to the literature many studies have discussed about the development of green product whereas substantial gaps still exist regarding effects of reactive and proactive green innovations on the performance development of green product (Kawai, Strange, \& Zucchella, 2018). So, we have tried to bridge that gap by suggesting a research framework with help of for innovative constructs: performance development of $\mathrm{Gl}$, green creativity, reactive $\mathrm{Gl}$ and proactive green innovation. Subsequently development of green products is most important for the firms at this time of environmentalism. The green production in Thailand has increases over the period of time (Figure 1).

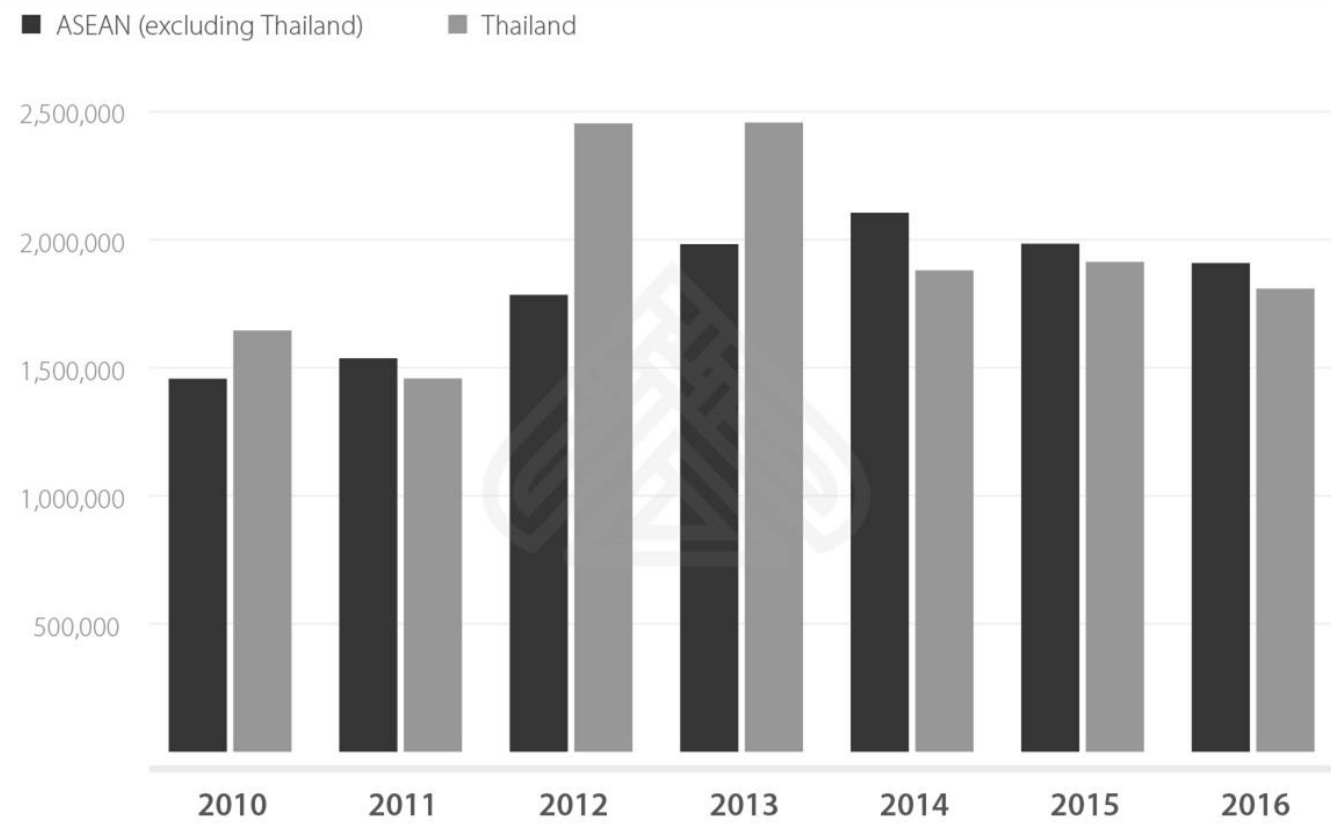

Figure 1. Green production Thailand Vs ASEAN. 
The framework of the current study will help the organizations to for the improvement of their performance development of green products through significant factors like green creativity and GI (Weng et al., 2015). In the current study we have followed may research steps. We have also summarized literature on first green product development (GPD), green creativity, reactive green innovation and proactive green innovation (Kerdawy, 2018). Then for verification of relationship between these variables we have also conducted empirical test. We have examined and purposed total five hypotheses. And at the end we have made discussions and conclusions regarding results their implementations and directions about future research. According to Seligman and Csikszentmihalyi (2014) trying to create benefits by taking initiative actions is known as proactive approach. Author have divided the GI into two different types: reactive and proactive GI. The active environment-associated innovation by taking initiatives for new products or practices before competitors for the cost reduction, to grab opportunities, leading in competitive market or achievement of competitive advantages is known as "Proactive green innovation". According to the Ottman (2017) organizations who are using the proactive strategies always takes preventive measures by introducing the new products and services in the market and become the leader of that competitive market. The organizations who just focus on profit-oriented approach they have to consider the environmental sustainability as per the policy of environment management because of increasing awareness about social environment. Jakhar (2017) have stated that the organizations who have ability of adopting new market trend have positive attitudes for the protection of environment and are not only in compliance with the regulations of environment protection. For the prevention of bad effects on environment the proactive initiatives of environmental management include introduction of different products and business operations and make predictions about social trends and future norms. In addition, usually with the innovative strategies brings the proactive environment. Which gives the number of opportunities to the organizations for leading with competitive advantages in the market (Proctor, 2014). The benefit of green innovations is comprising with lost cost to deal with pollution, the effectiveness and productivity will be high, accountability of law will be less developing the reputation of business and the stakeholder sad customers will provide additional support. In case of proactive management environment, the organizations should start investment in innovation, for incessant recycling of products and services in different systems (Kasim, 2015).

\section{HYPOTHESIS DEVELOPMENT}

Different thoughts and ideas regarding practices, process new products and services which are useful, innovative and original is known as creativity. Whereas the ability of introducing new things with unique art of creativity is known as innovation (Clapp, 2016). So, the innovation and creativity both are different things. Higher level of Corporate performance can be achieved with creativity. In addition, the competitive advantage can be obtained with high level of creativity (Basheer, Siam, Awn, \& Hassan, 2019). The ideas about green practices, process, products and services which can be arbitrated as useful, original and innovative. Weng et al. (2015) have stated that performance of corporate environmental management can be increased with Green innovation, means the organizations by using the proactive management may have the initiative of $\mathrm{Gl}$ as well. In environmental protection he foundation all green production is the green creativity, based on this we have assumed that green creativity can be positively affected by the proactive $\mathrm{Gl}$, and made the following hypothesis (Lam, Spreitzer, \& Fritz, 2014; Vafaei, Azmoon, \& Fekete-Farkas, 2019).

H1: the proactive green innovation significantly effects the green creativity.

For the companies the development/ growth of the product is very important, either it's the existing market or an emerging market. The development of product is main source of competitive advantage for organizations and with the diversified changes in market its important for the organizations to redesign their image (Benn, Edwards, \& Williams, 2014). According to the Stark (2015) for meeting the customer needs by changing the 
market opportunities is known as the product development. The main challenge for the organizations is the integration of product development and environment issues, and fulfilling the markets demands with obeying environmental regulations. For instance, has stated that a woman having children can only pay a small amount for environment friendly products whereas sometimes many customers are not ready to pay some extra amount for the environment friendly products. Additionally, Zhang and Zhu (2019) has also stated that organizations are expecting that where eco-innovation can be a failing strategy. Charter, Young, and Young (2017) has argued that the aim of developing the green products is reducing or decreasing the environmental burden with innovation and design of the product, and to answer the environmental issues it's an innovative and systematic method. Whereas organizations are trying to meet the customer needs related to the awareness of protecting the environment with the growth of environment friendly products and services. So, we have assumed that proactive $\mathrm{Gl}$ is positively related with the performance of GPD and made the following hypotheses.

H2: The proactive green innovation significantly affects the performance of the green product development.

According to Bangwal and Tiwari (2019) the organizations who are using the main post processing techniques and just obey the environmental laws, are mostly takes the inactive moves. The innovation related with passive environment with the purpose of following the environmental laws by adopting the requests of stake holders for alternative environment or by dealing the challenges of competitors is known as the reactive green innovation. According to Kim (2017) towards the environmental policies the passive attitude of organizations tends to have less responses of environment and time to time they just ignore the environmental problems. The organizations with passive attitudes for environmental management are just control the pollution on the basis of law. Moreover, usually the organizations with reactive approach are lacked with support of upper management or managers and they act only when there comes a problem. For handling the environmental issues customers can push organizations to make heavy investments ad pay extra attention to environment (Liu \& Atuahene-Gima, 2018). Whereas organizations passive attitude will not be upturned even passive organizations deal with strategies of responding customer needs. In short, the reactive strategy is inducing with $\mathrm{Gl}$ (Kasornbua and Pinsame, 2019). Though as compare to the proactive strategy, the reactive strategy competes with other organizations ad fulfil the customer demands on the basis of environmental laws. So, for the process of innovation development green creativity is important for environmental protection. Innovative but passive actions of organizations to fulfil the environment laws can positively affect the green creativity of stake holders. So, we have stated accordingly green creativity is associated with green innovation so have made the following hypothesis.

H3: The reactive green innovation significantly affects the green creativity.

According to Teece (2018) the base of successful business is development of product as it is a significant connection among the markets and companies. The organizations should manage the activities of product development strategically in competitive markets. But if organization is unable to manage the activities of product development then in future their business will be at high risk (Tidd \& Bessant, 2018). Additionally, the green products development is key source of competitive advantage either its allow cost production or related to product differentiation. Fedele and Antonucci (2015) argued that the reactivity and passiveness are undistinguishable the former are unable of catch the opportunity in top markets, and later on its timely reply or refuse the competition (Sarma et al., 2019). In environmental protection area by taking the environmental management of reactive organizations for the innovations will be up to the competitors and making modifications timely for getting rid of competitive environment. On the basis of above discussion, we have stated that performance of GPD is related with the reactive green innovation and made the following hypotheses.

H4: The reactive green innovation significantly affects the performance of the green product development. 
The positive effect on of GPDP by the green creativity the key driver of innovation for finding the innovative solutions is the organizational creativity. According to the literature team creativity is the main factor of success for a new product, the development of new product can be substitute with novelty and practicality. The ideas of organization which shows the improvement in performance of product development is creativity. Customer needs can be satisfied effectively with the advanced product development team having outstanding skills of creativity (Wilkinson \& De Angeli, 2014). New product development performance positively affected by the creativity. With the customer point of view. The idea of creativity is assessed by the targeted customers, the performance of new product development can be determined by the new ideas. Interaction of team members developed the group level creativity referred by the creativity team. Performance of the team is positively associated with the creativity team. Creativity is the foundation of innovations for the organizations. So according to the existing literature performance of new product development have positive association with creativity (Slater, Mohr, \& Sengupta, 2014).

The development performance of products which are formed from recycled mechanisms, are less harmful to human health, supply in market with less packaging, have less impact on the environment, , are made with less consumption of energy, or will supply to the market with less packaging" is known as GPDP. On the basis of the above discussion, we have made the following hypothesis:

H5: The green creativity significantly affects the performance of the green product development.

H6: Green creativity mediates the relationship between proactive green innovation and green product development.

H7: Green creativity mediates the relationship between reactive green innovation and green product development.

\section{METHODOLOGY AND MEASUREMENT}

\section{Sample and the Data Collection}

For the verification of hypothesis in sports industry of Thailand we have employed a surveyed questionnaire, for this survey we have used the postal services by examining the hypothesis by the period from 1 October 2018 to 31 January 2019. We have taken the participants from the different industries such as employees working in the companies of information services, electronics, software industries, communication equipment manufacturing , machinery and equipment manufacturing, food manufacturing, textiles mills, petrochemicals manufacturing, health care and biotech , optoelectronic materials and components manufacturing and so on in Thailand. From the business directory of Thailand, we have randomly selected the sample for the questionnaire survey. Respondent for our current study are managers of manufacturing department , R\&D, environmental, marketing departments, CEOs and leaders of different GPD projects, for the high response rate we have called to the nominated firms for the confirmation of job designations and names of respondents and we have also explained the objectives of the study in detail before sending the questionnaires. Additionally, in the current study, for the confirmation of high content validity we also undertake the two-round pretest. In this study the respondents are different for the constructs for reducing the common method variance (CMV). In the current study we have requested to all the respondents recognize a project of GPD which provide the maximum share in the company's account. Then it had also requested them to for assessing the project team regarding this project of green product development as an important one "performance of green product development", "green creativity", "reactive green innovation" and "proactive GI". The members for the project of GPD were the respondent for "reactive green innovation" and "proactive green innovation" (Kerdawy, 2018). And the leaders for the projects of green product development were the respondents for green creativity, and the respondents for the GPDP were managers, CEOs of marketing and 
R\&D departments of Thailand manufacturing industries. We had distributed total 200 questionnaires to the selected organizations, there were 146 questionnaire which were valid with response rate $37 \%$.

\section{Measurements of the Constructs and Definitions}

The questionnaire used in the current study have four measurement constructs like GPDP, innovation, green creativity, reactive green innovation and proactive green innovation and it was a "tick the box" survey. We have used a five-point Likert scale which ranges from "strongly agree" (1) and "strongly disagree" (5) for the questionnaire items measurement.

\section{Proactive green innovation}

AS per literature the innovative and proactive strategies or actions for having new products, cost reduction, taking new opportunities, gaining the competitive advantage or leading the market taking new measures towards environment is known as the proactive green innovation. There are four items in for measuring the proactive green innovation: (1) For obtaining the competitive advantage your organization is willingly implement the innovations regarding the environmental protection. (2) Your organization have actively improved the recycles, reuses, production process, ad for the cost reduction used the less amount of raw materials. (3) On the resources of environmental innovation Your organization actively involves in continuously thinking about becoming a pioneer by taking the opportunity successfully in the market. (4) Regarding the environmental protection your organization frequently have innovations by taking some new measures or leading over its competitors introduced new products.

\section{Reactive green innovation}

The innovation related with passive environment with the purpose of following the environmental laws by adopting the requests of stake holders or requirement of interested parties for alternative environment or by dealing the negative correlation of environmental innovation and challenges of competitors is known as the reactive green innovation. For the measurement of reactive green innovation, we have developed the fouritem measure (1) To compete with the rivals for the innovations related to environment your organization will be passive. (2) Your organization ever forced for responding the changed situations. (3) For the fulfilment of parties demands your organization have asked ever for the creation of new solutions. (4) To obey the environmental regulations your organization have ever adopted the environment linked innovations passively.

\section{Green creativity}

According to the Albort-Morant, Leal-Millán, and Cepeda-Carrión (2016) developing the new ideas regarding the green processes, green services, green products or the practices which are useful, innovative, novel and unique are known as green creativity (Weng et al., 2015). Th green creativity can easily measure with the help of six items. (1) The project members find out new ideas for the enhancement of environmental performance. (2) Real solutions for the environmental problems discovered by the project members. (3) For the implementation of new green ideas proper plans are created by the members of green project. (4) The project members support the new green ideas in front of others. (5) Rechecking of green ideas by the project members. (6) New ways for realizing the purpose of environmental protection by the members of the project.

\section{Green product development performance}

For the measurement of performance of green product development Albort-Morant et al. (2016) have developed a five-item measure: (1) The aims of GPD can be achieved by the project. (2) a compare to the competitors the project in the development of green product is more creative. (3) over the time the continuous improvements in the process of development by the project. (4) outstanding green products are discovered by the project. (5) The significant contribution of GPD in the revenues of organization. 


\section{DATA ANALYSIS}

By using the PLS algorithm in present study for the evaluating the reflective measurement model (MM)we had examined the data instrument. The PLS path model studied the evaluation criteria, appropriate reporting of results and suitable measurement model. By using the PLS-SEM we have measured the data for the judgement of quality with analytical abilities of theoretical research model.

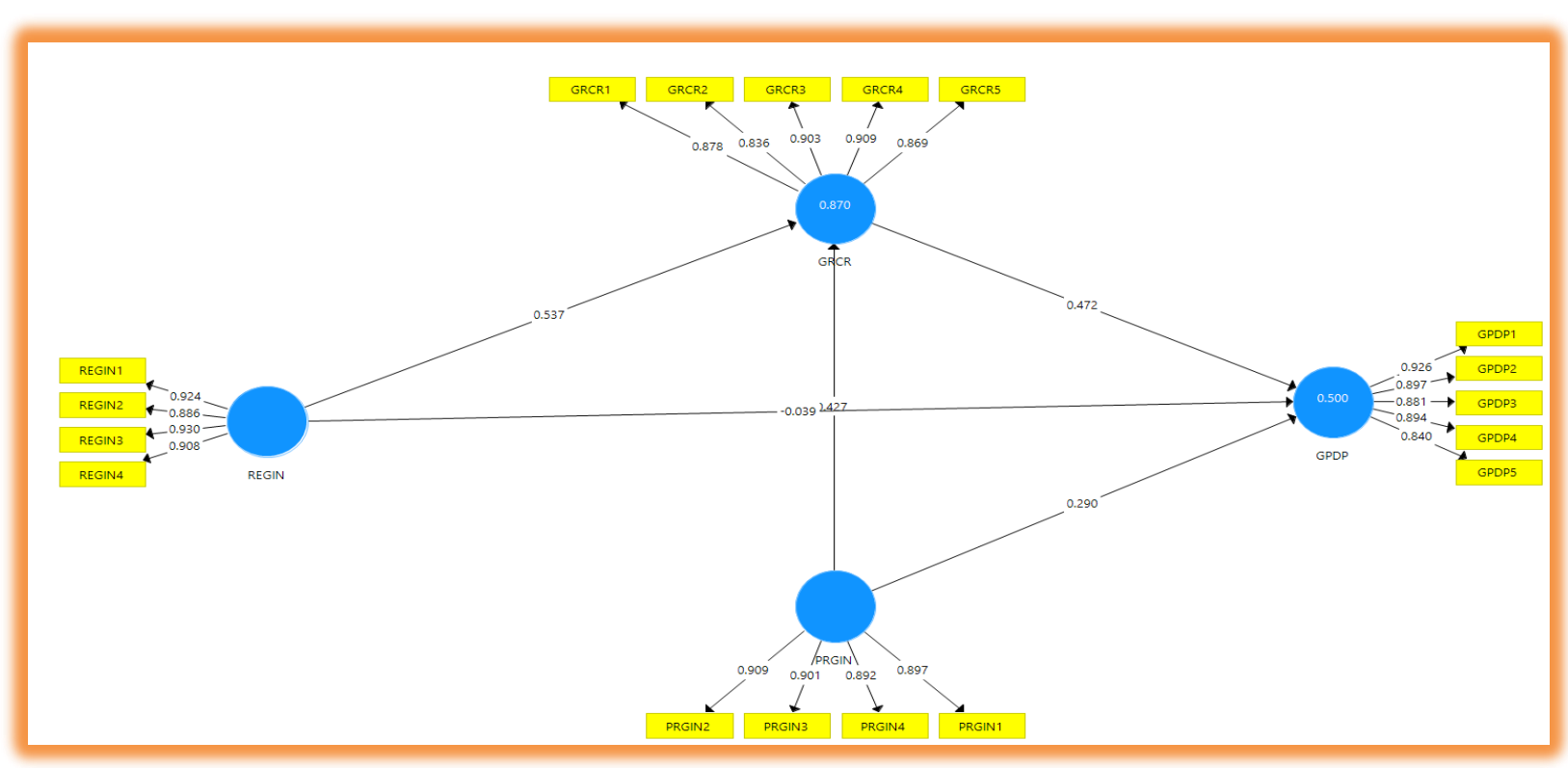

Figure 1. Measurement Model.

Table 1. Outer Loadings.

\begin{tabular}{|l|l|l|l|l|}
\hline & GPDP & GRCR & PRGIN & REGIN \\
\hline GPDP1 & 0.926 & & & \\
\hline GPDP2 & 0.897 & & & \\
\hline GPDP3 & 0.881 & & & \\
\hline GPDP4 & 0.894 & & & \\
\hline GPDP5 & 0.840 & & & \\
\hline GRCR1 & & 0.878 & & \\
\hline GRCR2 & & 0.836 & & \\
\hline GRCR3 & & 0.903 & & \\
\hline GRCR4 & & 0.909 & & \\
\hline GRCR5 & & 0.869 & & \\
\hline PRGIN2 & & & 0.909 & \\
\hline PRGIN3 & & & 0.901 & \\
\hline PRGIN4 & & & 0.892 & \\
\hline REGIN1 & & & & 0.924 \\
\hline REGIN2 & & & & 0.930 \\
\hline REGIN3 & & & & \\
\hline REGIN4 & & & & \\
\hline PRGIN1 & & & & \\
\hline
\end{tabular}


Measurement model measure the reliability and validity and facilitate the fair evaluation of the construct. For the evaluation of internal consistency (IC), and organizational indicator reliability in theoretical research model the composite reliability (CR) is involved and for the assessment of convergent validity (CV) and discriminant validity (DV) AVE is involved. CR is also known as the modern form of Cronbach alpha that is ICR. Indicators of observed variables provides the estimates of reliability based on inter correlation. High level of reliability indicates the high value, and it lies between 0 and 1. According to Lonial and Carter (2015) that the acceptable values of $\mathrm{CR}$ in exploratory research are from 0.60 to 0.70 , while as per the modern research the values 0.70 to 0.90 are also satisfactory. We have measured and established the CV by using the AVE values, that is equal to the communality of the construct. The AVE values which are greater than or equal to the 0.50 indicates that the construct on average shows that in the variable the greater than half of the total change. And similarly, the value of AVE is less than 0.50 it indicates that on average additional errors remain in the items related to the change notified by the construct. As the evaluation criterion the AVE values build the assessment of $\mathrm{CV}$. On the construct the high values of outer loading indicate that there is a lot of same in related indicators that is also known as indicator reliability. The variables outer loadings should be statistically significant with values that are higher than the 0.708 , this shows that measurement error change is less than the change in construct. According to the Davcik and Sharma (2016), when the when the value of composite reliability and AVE is greater than the threshold level, the values between the 0.40 and 0.70 must be deleted.

Table 2. Reliability.

\begin{tabular}{|l|l|l|l|l|}
\hline & Cronbach's Alpha & rho_A & CR & (AVE) \\
\hline GPDP & 0.933 & 0.934 & 0.949 & 0.789 \\
\hline GRCR & 0.926 & 0.928 & 0.944 & 0.773 \\
\hline PRGIN & 0.922 & 0.922 & 0.945 & 0.810 \\
\hline REGIN & 0.933 & 0.935 & 0.952 & 0.832 \\
\hline
\end{tabular}

Tale 3. Validity.

\begin{tabular}{|l|l|l|l|l|}
\hline & GPDP & GRCR & PRGIN & REGIN \\
\hline GPDP & 0.888 & & & \\
\hline GRCR & 0.796 & 0.879 & & \\
\hline PRGIN & 0.778 & 0.875 & 0.900 & \\
\hline REGIN & 0.743 & 0.809 & 0.872 & 0.902 \\
\hline
\end{tabular}

The main focus of this study is on theoretical model which indicate the underlying theory of path model. The assessment results will decide that how theoretical framework is maintained by the empirical data and explained in detail that either the phenomena is explained by the theory well. After the verification of construct validity and reliability, we have evaluated the theoretical research model further. That is involved in assessment of analytical capabilities of model and relationship between variables. In PLS-SEM for the assessment of structural model (SC) the important criteria are the level of R square values, significance of path coefficient, $q^{2}$ affect size, analytical relevance $Q^{2}$ and the effect size of $f^{2}$.

From the SM association we have obtained estimates for the analysis of PLS-SEM, which shows the hypothesized relationship among the variables, there are total 129 standard values of path coefficients between -1 to +1 . Path coefficient values that are close to +1 indicates the strong positive relationship while the values close to -1 indicates the negative relationship. However, the path coefficients can estimate the significance of variables which ultimately depend on the standard errors of bootstrapping. In the process of bootstrapping the subsamples are strained from the original set of data randomly. Then use each subsample 
for model estimation and have repeated this process for creating number of subsamples. In the current study we have also reported the $p$ values and excluded the estimation of $t$ values. Which are similar to the rejection of null hypothesis.

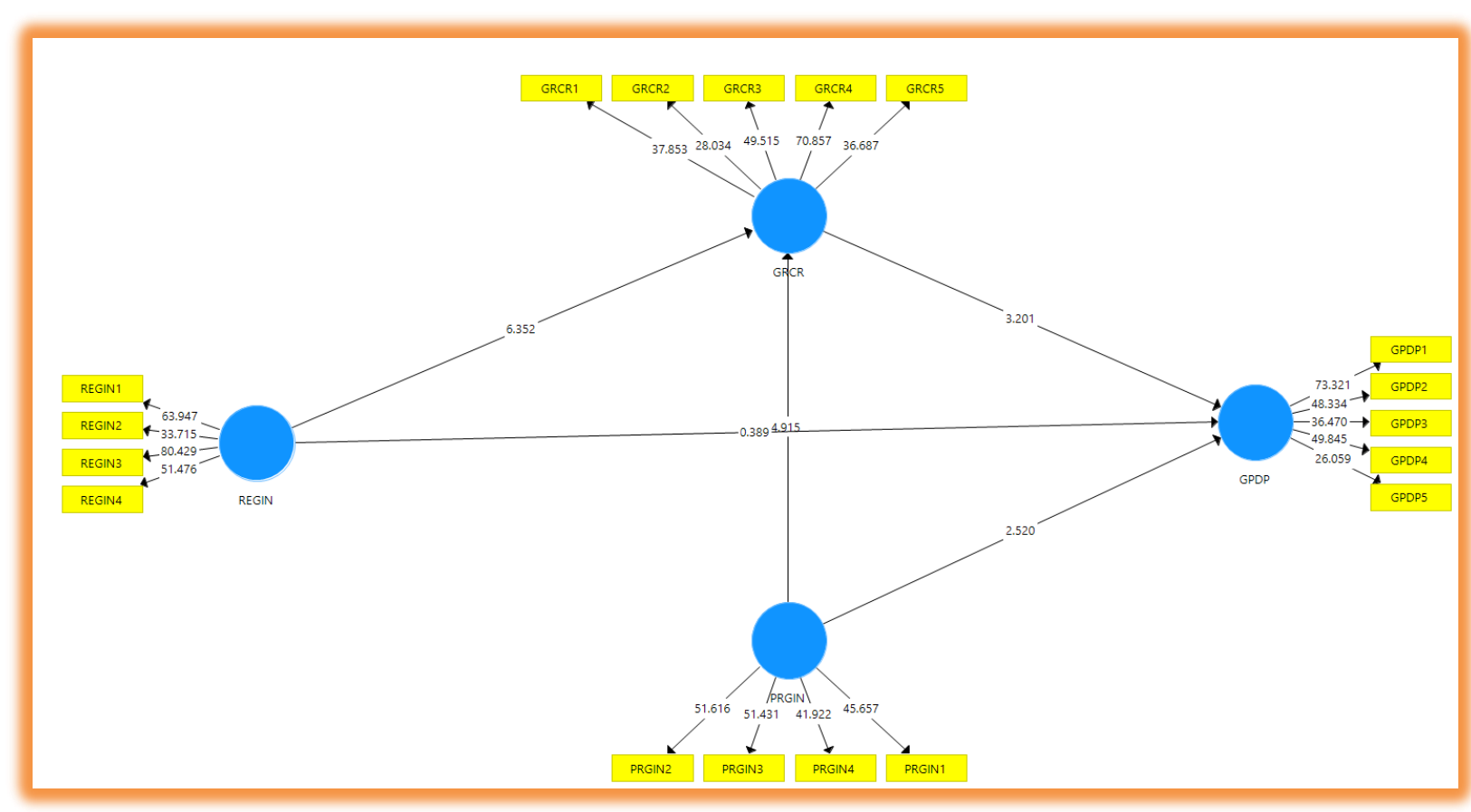

Figure 2. Structural Model.

Table 4. Direct Results.

\begin{tabular}{|l|l|l|l|l|l|}
\hline & $(\mathbf{O})$ & $\mathbf{( M )}$ & (STDEV) & (|O/STDEV $\mid)$ & P Values \\
\hline GRCR -> GPDP & 0.472 & 0.467 & 0.147 & 3.201 & $\mathbf{0 . 0 0 1}$ \\
\hline PRGIN -> GPDP & 0.290 & 0.288 & 0.115 & 2.520 & $\mathbf{0 . 0 0 6}$ \\
\hline PRGIN -> GRCR & 0.427 & 0.424 & 0.087 & 4.915 & $\mathbf{0 . 0 0 0}$ \\
\hline REGIN -> GPDP & -0.039 & -0.030 & 0.100 & 0.389 & $\mathbf{0 . 3 4 9}$ \\
\hline REGIN -> GRCR & 0.537 & 0.540 & 0.084 & 6.352 & $\mathbf{0 . 0 0 0}$ \\
\hline
\end{tabular}

Table 5. Mediation.

\begin{tabular}{|l|l|l|l|l|l|}
\hline & $(\mathbf{O})$ & $(\mathbf{M})$ & $($ STDEV $)$ & $($ |O/STDEV $)$ & P Values \\
\hline PRGIN -> GRCR -> GPDP & 0.201 & 0.199 & 0.078 & 2.598 & $\mathbf{0 . 0 0 5}$ \\
\hline REGIN -> GRCR -> GPDP & 0.253 & 0.251 & 0.087 & 2.915 & $\mathbf{0 . 0 0 2}$ \\
\hline
\end{tabular}

We have used the coefficient of determination for the estimation of SM, which is the accuracy level of analytical model and among the actual and predicted values of independent variables we have also measure the square correlation. The mutual effect of dependent and independent variable is indicated by the coefficients. And variance in dependent variable is linked with the independent variable. The $r$ square value lies between 0to 1, high level of accuracy indicated by the high values. In this study the higher predictive accuracy is if the value of $R$ square is greater or equal to 0.20 . in addition, for the values of $R$ square the criteria is evaluation of scale. 
Table 6. R-square.

\begin{tabular}{|l|l|}
\hline & R Square \\
\hline GPDP & 0.500 \\
\hline GRCR & 0.870 \\
\hline
\end{tabular}

The values of $Q$ square are also determined in this study, for the theoretical research model which are the indicator of predictive significance. In theoretical research model for some DV's values of $Q^{2}$ are greater than 0 which indicate the significance of path model, by using the blindfolding procedure from certain distance of omission we have obtained the $Q$ square values.

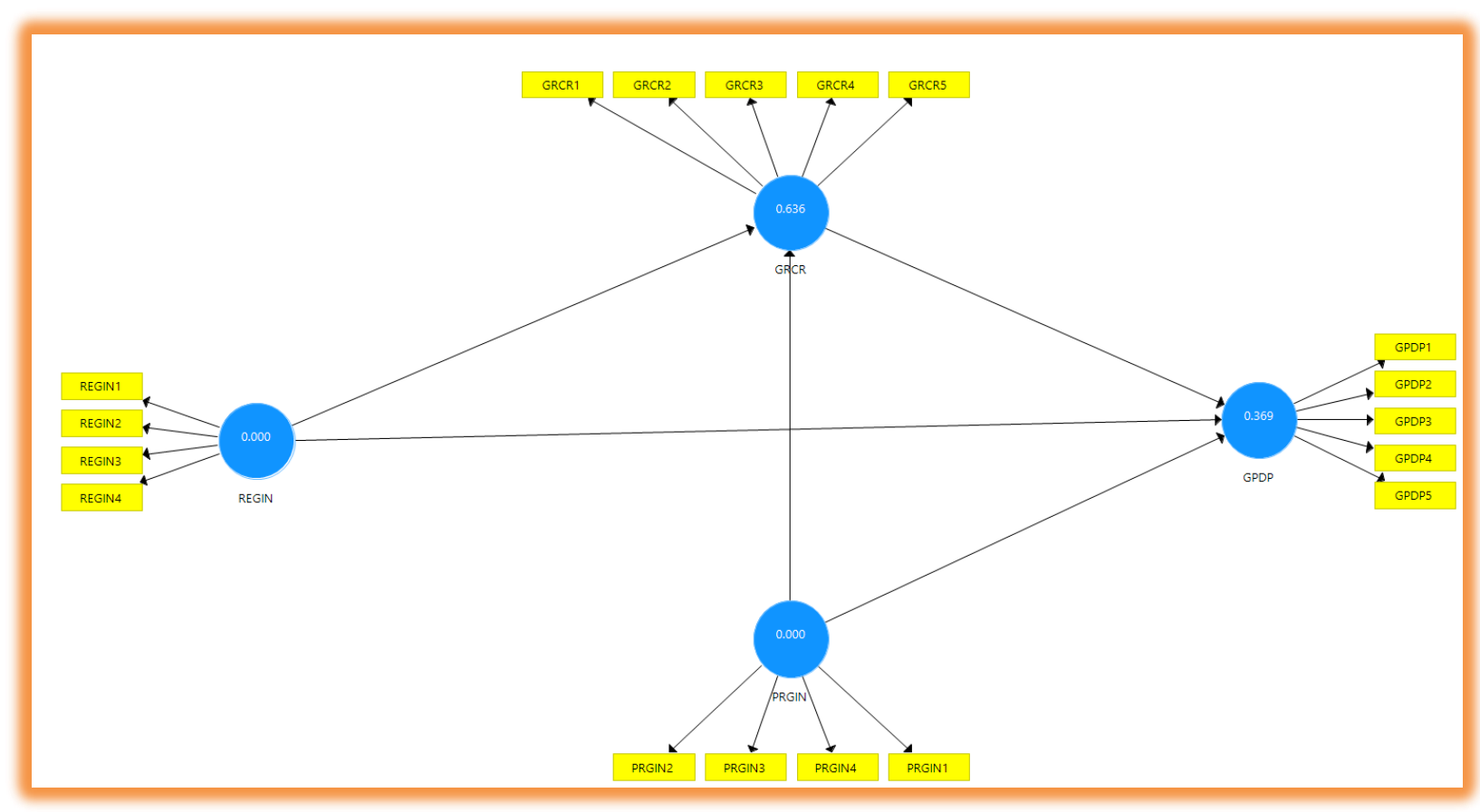

Figure 3. Q-square.

Table 7. Q-square.

\begin{tabular}{|l|l|l|l|}
\hline & SSO & SSE & $\mathbf{Q}^{2}$ (=1-SSE/SSO) \\
\hline GPDP & $1,085.000$ & 684.392 & 0.369 \\
\hline GRCR & $1,085.000$ & 395.350 & 0.636 \\
\hline
\end{tabular}

\section{RESULTS}

Because of there is a research gap between GPDP and green product innovation, the current study has scrutinized the research framework to focused on how the reactive ad proactive green innovation (PGI) affect the performance of green product development in environmental era over the green creativity. According to the findings of the current study GPDP and green creativity both are positively related with the PGI, and between the GPDP and PGI, there is partial mediator role of green creativity. If the organizations make heavy investments on resources for increasing the green proactive innovations, they can achieve improved product development performance (Lee \& Min, 2015). In addition, according to the results the organizations along with high PGI, the green creativity mediates between the association of GPDP and PGI. Whereas GPDP and 
green creativity are not significantly influenced by reactive green innovation. So, for increasing their product development performance and enhancement of green creativity organizations must focus on developing the green innovations as compere to reactive green innovations. The results of the current study will contribute in literature in ways. Firstly, on the basis of results of association between product development performance and green creativity, the current study will collect more information in this domain with the addition of more related variables for example in the research framework by taking the reactive green innovation and PGI as ancestor variables. Secondly as per empirical results we have found that that effect of reactive green innovation is different from the proactive green innovation (Worrell, 2018), by which we can fill the gap of earlier studies. Thirdly the association between the GPDP and PGI is partially mediated by the green creativity which shows the vital role of green creativity in the organizations who are pursing the GPDP. And fourthly because the GPDP and green creativity are not significantly influenced by the green innovation so for the enhancement of GPDP and green creativity the organizations must develop PGI instead of reactive green innovation. The current study will also make four practical contributions, which will be beneficial for the green product development of organizations. The results indicate that for the GPDP and green creativity PGI is very important, so for the enhancement of GPDP and even green creativity setting up strategies, interventions ad goals which are essential for the organizations in becoming trained with proactive green innovation (Kerdawy, 2018). Consequently, from the green products if the organizations want to earn profit they have to be attentive in building an organizational society of proactive green innovations for instance for the green innovations organizations must have to start investing their non-financial ad financial resources for leading their top position in the competitive market (Ciocirlan, 2018; Weng et al., 2015). The organizations must have to redesign their work process, recycle the useful resources, make strategic plans and save the energy. There will be a change in competitive markets because of the PGI culture. The performance of sustainability will be affected with the collective environmental governance. The performance of green product development is expected with the PGI culture. Secondly for increasing the proactivity of employees for green product innovation some advanced approaches must be incorporated because of the significance of PGI culture, for instance in the organizations the provision of well-designed training can help the employees for having awareness regarding the culture of PGI in the organizations. Thirdly between the green product development performance and PGI there is an important role of green creativity, as in organizations increment in green creativity also matters a lot. For the cumulative green activity Some managerial mediations like reimbursement plans, brainstorming competitions and team building are might be good options (Papp, 2018). For the future research author can use the longitudinal study and can make discussion about differences of the finding in different time period. Secondly the research can conduct a study on different countries and compare the finding with current study. For the future study in conceptual framework human resource practices can also be considered.

\section{REFERENCES}

Albort-Morant, G., Leal-Millán, A., \& Cepeda-Carrión, G. (2016). The antecedents of green innovation performance: A model of learning and capabilities. Journal of Business Research, 69(11), 49124917. https://doi.org/10.1016/j.jbusres.2016.04.052

Bangwal, D., \& Tiwari, P. (2019). Environmental design and awareness impact on organization image. Engineering, Construction and Architectural Management, 26(1), 29-45. https://doi.org/10.1108/ecam-02-2017-0029

Basheer, M., Siam, M., Awn, A., \& Hassan, S. (2019). Exploring the role of TQM and supply chain practices for firm supply performance in the presence of information technology capabilities and supply chain technology adoption: A case of textile firms in Pakistan. Uncertain Supply Chain Management, 7(2), 275-288. https://doi.org/10.5267/j.uscm.2018.9.001 
Benn, S., Edwards, M., \& Williams, T. (2014). Organizational change for corporate sustainability: Routledge.

Charter, M., Young, A., \& Young, A. (2017). Integrated product policy and eco-product development Sustainable Solutions (pp. 98-116): Routledge. https://doi.org/10.9774/gleaf.978-1-907643-21-7 7

Ciocirlan, C. E. (2018). Green human resources management Research Handbook on Employee ProEnvironmental Behaviour (pp. 39): Edward Elgar Publishing. https://doi.org/10.4337/9781786432834.00008

Clapp, E. P. (2016). Participatory creativity: Introducing access and equity to the creative classroom: Routledge. https://doi.org/10.4324/9781315671512

Davcik, N. S., \& Sharma, P. (2016). Marketing resources, performance, and competitive advantage: A review and future research directions. Journal of Business Research, 69(12), 5547-5552. https://doi.org/10.1016/j.jbusres.2016.04.169

Fedele, M., \& Antonucci, E. (2015). The life of corporations and the economic-financial modern context. By the decline to the business crisis. International Journal of Management Sciences and Business Research, 4(1).

Haseeb, M., Kot, S., Hussain, H., \& Jermsittiparsert, K. (2019). Impact of Economic Growth, Environmental Pollution, and Energy Consumption on Health Expenditure and R and D Expenditure of ASEAN Countries. Energies, 12(19), 3598. https://doi.org/10.3390/en12193598

Jakhar, S. K. (2017). Stakeholder engagement and environmental practice adoption: The mediating role of process management practices. Sustainable Development, 25(1), 92-110. https://doi.org/10.1002/sd.1644

Jermsittiparsert, K. \& Chankoson, T. (2019). Behavior of Tourism Industry under the Situation of Environmental Threats and Carbon Emission: Time Series Analysis from Thailand. International Journal of Energy Economics and Policy, 9(6), 366-372. https://doi.org/10.32479/ijeep.8365

Kasayanond, A., Umam, R., \& Jermsittiparsert, K. (2019). Environmental Sustainability and its Growth in Malaysia by Elaborating the Green Economy and Environmental Efficiency. International Journal of Energy Economics and Policy, 9(5), 465-473. https://doi.org/10.32479/ijeep.8310

Kasim, A. (2015). Environmental management system (EMS) Postulating the value of its adoption to organizational learning in hotels. International Journal of Contemporary Hospitality Management, 27(6), 1233-1253. https://doi.org/10.1108/ijchm-01-2014-0045

Kawai, N., Strange, R., \& Zucchella, A. (2018). Stakeholder pressures, EMS implementation, and green innovation in MNC overseas subsidiaries. International Business Review, 27(5), 933-946. https://doi.org/10.1016/j.ibusrev.2018.02.004

Kerdawy, M. M. A. (2018). The role of corporate support for employee volunteering in strengthening the impact of green human resource management practices on corporate social responsibility in the Egyptian firms. European Management Review. https://doi.org/10.1111/emre.12310

Kim, Y. (2017). Consumer responses to the food industry's proactive and passive environmental CSR, factoring in price as CSR tradeoff. Journal of Business Ethics, 140(2), 307-321. https://doi.org/10.1007/s10551-015-2671-8

Karle Pravin P, Dhawale Shashikant C. "Manilkara zapota (L.) Royen Fruit Peel: A Phytochemical and Pharmacological Review." Systematic Reviews in Pharmacy 10.1 (2019), 11-14. https://doi.org/10.5530/srp.2019.1.2

Kasornbua, T., Pinsame, Ch. 2019. Factors affecting purchase intention of community product in Thailand-Cambodia border. Entrepreneurship and Sustainability Issues, 7(2), 949-961. http://doi.org/10.9770/jesi.2019.7.2(11)

Lucangioli.S. "Acute Renal Failure: An Article Critique." International Journal of Pharmacy Research \& Technology 8.2 (2018), 51-52. https://doi.org/10.31838/ijprt/08.02.07 
Lam, C. F., Spreitzer, G., \& Fritz, C. (2014). Too much of a good thing: Curvilinear effect of positive affect on proactive behaviors. Journal of Organizational Behavior, 35(4), 530-546. https://doi.org/10.1002/job.1906

Lee, K.-H., \& Min, B. (2015). Green R\&D for eco-innovation and its impact on carbon emissions and firm performance. Journal of Cleaner Production, 108, 534-542. https://doi.org/10.1016/j.jclepro.2015.05.114

Liu, W., \& Atuahene-Gima, K. (2018). Enhancing product innovation performance in a dysfunctional competitive environment: The roles of competitive strategies and market-based assets. Industrial Marketing Management, 73, 7-20. https://doi.org/10.1016/j.indmarman.2018.01.006

Lonial, S. C., \& Carter, R. E. (2015). The impact of organizational orientations on medium and small firm performance: A resource-based perspective. Journal of Small Business Management, 53(1), 94-113. https://doi.org/10.1111/jsbm.12054

Mathiyazhagan, K., Sengupta, S., \& Mathivathanan, D. (2019). Challenges for implementing green concept in sustainable manufacturing: a systematic review. OPSEARCH, 56(1), 32-72. https://doi.org/10.1007/s12597-019-00359-2

Ottman, J. (2017). The new rules of green marketing: Strategies, tools, and inspiration for sustainable branding: Routledge. https://doi.org/10.4324/9781351278683

Papp, J. (2018). Quality Management in the Imaging Sciences E-Book: Elsevier Health Sciences.

Proctor, T. (2014). Strategic marketing: an introduction: Routledge.

Sarma, U.; Karnitis, G.; Zuters, J.; Karnitis, E. 2019. District heating networks: enhancement of the efficiency, Insights into Regional Development 1(3): 200-213. https://doi.org/10.9770/ird.2019.1.3(2)

Seligman, M. E., \& Csikszentmihalyi, M. (2014). Positive psychology: An introduction Flow and the foundations of positive psychology (pp. 279-298): Springer. https://doi.org/10.1007/978-94-0179088-8_18

Slater, S. F., Mohr, J. J., \& Sengupta, S. (2014). Radical product innovation capability: Literature review, synthesis, and illustrative research propositions. Journal of Product Innovation Management, 31(3), 552-566. https://doi.org/10.1111/jpim.12113

Somjai, S. \& Jermsittiparsert, K. (2019). The Trade-off between Cost and Environmental Performance in the Presence of Sustainable Supply Chain. International Journal of Supply Chain Management, 8(4), $237-247$.

Stark, J. (2015). Product lifecycle management Product lifecycle management (Volume 1) (pp. 1-29): Springer. https://doi.org/10.1007/978-3-319-17440-2_1

Teece, D. J. (2018). Business models and dynamic capabilities. Long Range Planning, 51(1), 40-49. https://doi.org/10.1016/.l.rp.2017.06.007

Tidd, J., \& Bessant, J. R. (2018). Managing innovation: integrating technological, market and organizational change: John Wiley \& Sons.

Vafaei, S. A., Azmoon, I., \& Fekete-Farkas, M. (2019). The impact of perceived sustainable marketing policies on green customer satisfaction. Polish Journal of Management Studies, 19. https://doi.org/10.17512/pims.2019.19.1.36

Weng, H.-H., Chen, J.-S., \& Chen, P.-C. (2015). Effects of green innovation on environmental and corporate performance: A stakeholder perspective. Sustainability, 7(5), 4997-5026. https://doi.org/10.3390/su7054997

Wilkinson, C. R., \& De Angeli, A. (2014). Applying user centred and participatory design approaches to commercial product development. Design Studies, 35(6), 614-631. https://doi.org/10.1016/j.destud.2014.06.001

Worrell, J. H. (2018). Exploring luxury fashion brands' strategic response to crisis: a multiple case study on surviving the Global Financial Crisis. Colorado State University. Libraries. 
Zhang, F., \& Zhu, L. (2019). Enhancing corporate sustainable development: Stakeholder pressures, organizational learning, and green innovation. Business Strategy and the Environment, 28(6), 10121026. https://doi.org/10.1002/bse.2298

\section{(c) 7 (†) $९$}

This work is licensed under a Attribution-NonCommercial-NoDerivatives 4.0 International (CC BY-NC-ND 4.0). 